\title{
EVALUACIÓN DEL CONFORT TÉRMICO EN VIVIENDAS CON CERRAMIENTOS DE MAMPOSTERÍA DE LADRILLO CERÁMICO
}

\section{Bernardo Cabrerizo Barrientos}

\section{RESUMEN}

El trabajo se enfoca en el confort térmico de viviendas construidas en ladrillo cerámico, para el clima de la ciudad de Cochabamba. El objetivo del estudio fue realizar la evaluación del confort térmico de viviendas construidas en ladrillo cerámico, de manera de identificar las características y necesidades que permitan plantear alternativas bioclimáticas para el diseño y construcción de viviendas, considerando las variables que intervienen y determinan la confortabilidad térmica - variables externas medioambientales, variables internas (envolvente), parámetros arquitectónicos y variable hombre (usuario). En base al estudio de estas variables, se realizó la evaluación del confort térmico de viviendas seleccionadas en la ciudad de Cochabamba, determinándose el comportamiento térmico mediante mediciones de campo, análisis, simulaciones informáticas y evaluación. A partir de esa evaluación, se plantearon recomendaciones a ser consideradas en el diseño arquitectónico para lograr la confortabilidad térmica para el clima de la ciudad de Cochabamba.

Palabras Clave: Confort Térmico, Arquitectura Bioclimática, Sistemas Pasivos de Diseño. 